\title{
Estimation of Dry Deposition during Asian Dust Events in Spring of 2002
}

\author{
Sang-Sam LEE*, Youngsin CHUN, Jae-Cheol NAM \\ Meteorological Research Institute, Korea Meteorological Administration, Seoul, KOREA \\ and \\ Soon-Ung PARK, Eun-Hee LEE \\ School of Earth and Environmental Sciences, Seoul National University, Seoul, KOREA
}

(Manuscript received 13 October 2004, in final form 19 February 2005)

\begin{abstract}
Dry deposition of Asian dust has been estimated during the intensive dust events in spring 2002 (Period I: 15-24 March 2002, Period II: 4-13 April 2002) using the Asian dust aerosol model (ADAM). The emission module including log-normal distributions of particle size of different soil types of Gobi, Sand, Loess, and Mixed soil in the Asian dust source regions, has been used to calculate the amount of dry deposition. The dry deposition estimated by ADAM is compared with that calculated by using the optical particle counter (OPC) observed at Anmyeondo in Korea. The correlation between the modeled and the calculated dry deposition, is found to be 0.78 and 0.54 in Periods I and II, respectively. The dry deposition velocity depends on the particle size with a minimum value of $0.0272 \mathrm{~cm} \mathrm{~s}^{-1}$ and $0.0269 \mathrm{~cm} \mathrm{~s}^{-1}$ in the size range of $0.82-1.35 \mu \mathrm{m}$ in diameter in Periods I and II, respectively. The averaged spectral distribution of dry deposition indicates that the larger particles are more contributed to the total dry deposition amount than the smaller particles due to the large deposition velocity of larger particles. Consequently, the dry deposition rate is found to be higher in regions closer to the Asian dust source regions.

The estimated total dry deposition amounts over the South Korea, North Korea and Japan are found to be about 558, 955, and $729 \mathrm{k}$ ton, in Period I, respectively and about 240, 364, and $196 \mathrm{k}$ ton, in Period II, respectively.
\end{abstract}

Keywords: Asian dust (Hwangsa); Asian dust aerosol model (ADAM); Dry deposition; Deposition velocity; Optical particle counter (OPC).

\section{Introduction}

Asian dust, also termed as 'Hwangsa' in Korea and 'Kosa' in Japan, is a typical example of mineral aerosol frequently originating in the Gobi desert, Sand desert, Loess plateau and barren mixed soil in Mongolia and northern

* Corresponding author: Sang-Sam Lee, Applied Meteorology Research Laboratory, Meteorological Research Institute/KMA 460-18, Shindaebangdong, Dongjak-ku, Seoul 156-720, KOREA. E-mail: leess@metri.re.kr

(C) 2005, Meteorological Society of Japan
China during the spring season (Chun et al. 2001a; In and Park 2002; Park and In 2003). In recent years, more intense and frequent dust storms in East Asia have increased with the gradual increase in arid desertification due in part to heavy cultivation, overgrazing and lack of precipitation in the source regions (Bai and Zhang 2001; Park 2002; Chun et al. 2003). Indeed, very severe dust storms were observed in Korea on 21-23 March and 7-9 April 2002 (Chun et al. 2004). During these periods the observed $\mathrm{PM}_{10}$ concentrations were over $1,000 \mu \mathrm{g} \mathrm{m}^{-3}$ at most monitoring sites in South Korea (In and Park 2003; Park and In 2003). 
These were more than 10 times higher than those of the non-dust storm period, thereby causing natural disasters, including temporary closing of most domestic airports and elementary schools in Korea.

An improved dust emission model depending on the particle-size distribution by the sum of three log normal distributions of particle size in different soil types such as Gobi, Sand, Loess and Mixed soil in the Asian dust source region has been developed and successfully simulated to two intense dust events that have been observed in Korea in March (Park and Lee 2004) and April 2002 (In and Park 2003). This model, so called the Asian Dust Aerosol Model (ADAM; a three-dimensional eulerian transport model), will be employed to estimate dry deposition of Asian dust in East Asia.

Dust particles emitted from the source region settle as dry deposition when precipitation does not occur. The estimated atmospheric loadings of 23-24 April 1993 over the Korean peninsula were about 1.5 Mton (Chung and Yoon 1996).

The purpose of this study is to estimate dry deposition over the Korean peninsula and Japan by ADAM for severe dust events that have been observed during the spring of 2002. The modeled dry deposition will be compared with that estimated by the particle numbers measurements at Anmyeondo in Korea.

\section{Data and parameterization}

\subsection{Data}

The meteorological field data used in this study is obtained from the operational meteorological model for the Regional Data Assimilation and Prediction System (RDAPS) in Korea Meteorological Administration (KMA). These data are based on the MM5 version 3 that uses the $x, y$, and $\sigma$ coordinate with a horizontal resolution of $30 \mathrm{~km}$ and 33 vertical layers up to the $50 \mathrm{hPa}$ level (Grell et al. 1994; Duhdia et al. 2001). Since dust is emitted and transported from the surface, only 25 vertical layers from the surface are used in this study.

RDAPS involves non-hydrostatic primitive physical equations of momentum, thermodynamics and moisture with physical processes including the Kain-Fritsch scheme for convective parameterization, the mixed-phase scheme for moisture explicit scheme, the nonlocal boundary layer scheme for the planetary boundary layer processes and the cloud-cooling scheme for radiation.

Two intense Asian dust events have been observed in the spring of 2002 in East Asia region. One is observed from 15 to 24 March and the other from 4 to 13 April 2002. For our convenience, we call the former dust period as Period I and the latter as Period II for the estimation of dry deposition of dust. At the same time, the spectral number concentrations were measured at Anmyeondo in Korea for both periods using the optical particle counter (OPC, HIAC/ ROYCO 5230) operated routinely since the spring of 1998 (Chun et al. 2001a, 2001b). The OPC has 8 size bins $(0.3-0.5,0.5-0.82,0.82-$ $1.35,1.35-2.23,2.23-3.67,3.67-6.06,6.06-10$, and $10-25 \mu \mathrm{m}$ in diameter) with the same logscale interval.

\subsection{Parameterization of dry deposition}

ADAM (In and Park 2002; Park and In 2003) has been improved from the spectral dust emission estimated by power law (Westphal et al. 1987, 1988) with the concept of the minimally and fully dispersed parent soil particle size distribution. The particle-size distribution suspended in the air is a weighted average of minimally and fully dispersed parent soil particle-size distribution ( $\mathrm{Lu}$ and Shao 1999; Shao 2001; Shao et al. 2002). The minimally and fully dispersed particle-size distribution in the ADAM model is expressed by the sum of several log-normal distributions of particles size of different soil types of Gobi, Sand, Loess, and Mixed soil that are obtained from the samplings in the source regions (Park 2002; Park and In 2003; Park and Lee 2004) with the help of the Chinese soil map (Yi 1986).

In calculating dry deposition, particles of $0.2-74 \mu \mathrm{m}$ in diameter are divided into 11 size bins $(0.2-0.5,0.5-0.82,0.82-1.35,1.35-2.23$, $2.23-3.67,3.67-6.06,6.06-10,10-16.5,16.5-$ $27.25,27.25-45$, and $45-74 \mu \mathrm{m}$ in diameter) with the same logarithmic interval.

The deposition of particles upon the surface without precipitation is resisted by the aerodynamic and quasi-laminar (Seinfeld and Pandis 1998) resistance. The aerodynamic resistance $\left(R_{a}\right)$ is determined by the atmospheric turbulence intensity that depends largely on the micrometeorological characteristics such as lower atmospheric stability and the surface rough- 
(a)
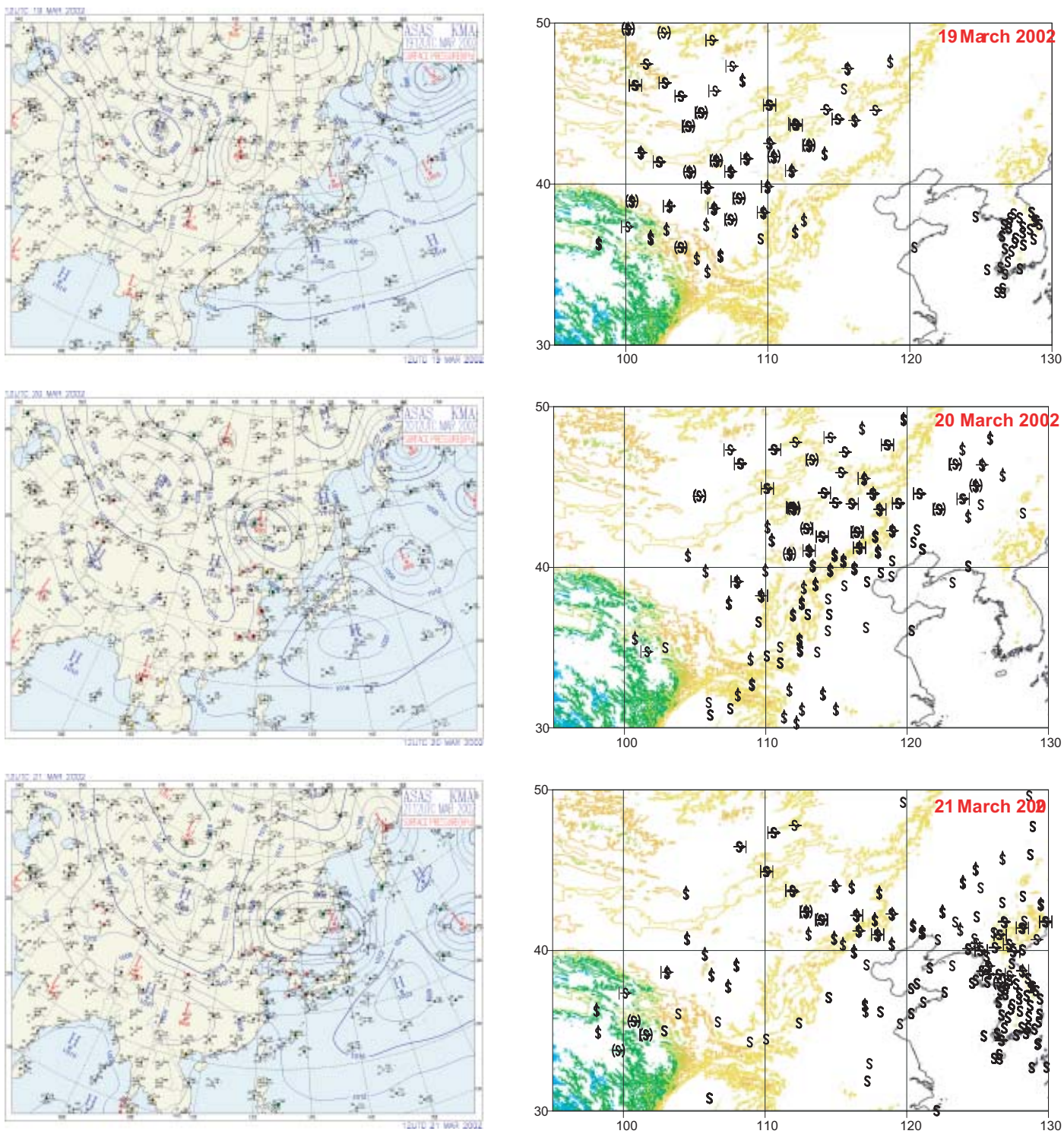

Fig. 1. Surface synoptic weather maps (left panel) and dust reporting maps (right panel) on (a) 19, 20, and 21 March and (b) 7, 8, and 9 April 2002.

ness. In addition, the particles adjacent to the surface across a quasi-laminar larger experience the quasi-laminar resistance $\left(R_{b}\right)$ that depends largely on molecular properties of the substance and surface characteristics. Deposition of larger particles (larger than $20 \mu \mathrm{m}$ in diameter) are mainly controlled by the gravitational settling velocity $\left(V_{g}\right)$ since the settling velocity increases with the square of the particle diameter.
The dry deposition flux is estimated from the dry deposition velocity $\left(V_{d}\right)$ and the airborne concentration $(C)$ near the surface; i.e.

$$
F=V_{d} \cdot C
$$

The dry deposition velocity $\left(V_{d}\right)$ is parameterized using the resistance method that is a little different for gaseous species and particulate (Wesely and Hicks 1977; Wesely and Hicks 
(b)
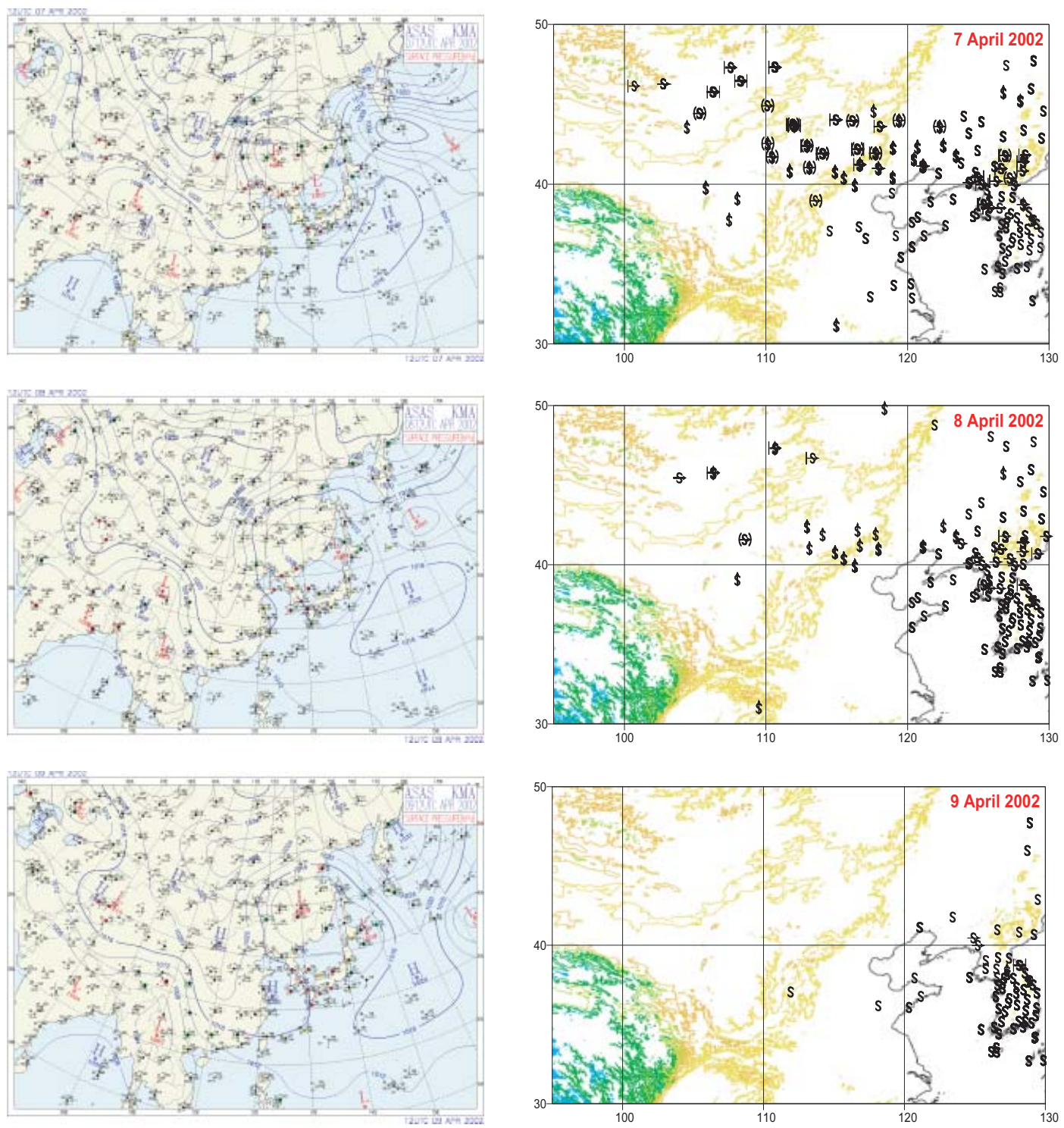

Fig. 1 (continued)

2000; Wesely et al. 1985; Seinfeld and Pandis 1998). The dry deposition velocity for particles is expressed as

$$
V_{d}=\frac{1}{R_{a}+R_{b}+R_{a} R_{b} V_{g}}+V_{g}
$$

where $R_{a}$ is the aerodynamic resistance, $R_{b}$ is the quasi-laminar resistance, and $V_{g}$ is the gravitational settling velocity. The aerodynamic resistance is parameterized as:

$$
R_{a}= \begin{cases}\frac{1}{k u_{*}}\left[\ln \left(\frac{z}{z_{0}}\right)+4.7\left(\zeta-\zeta_{0}\right)\right] & \text { for stable } \\ \frac{1}{k u_{*}} \ln \left(\frac{z}{z_{0}}\right) & \text { for neutral } \\ \frac{1}{k u_{*}}\left[\ln \left(\frac{z}{z_{0}}\right)+\ln \left\{\frac{\left(\eta_{0}^{2}+1\right)\left(\eta_{0}+1\right)^{2}}{\left(\eta_{r}^{2}+1\right)\left(\eta_{r}+1\right)^{2}}\right\}\right. \\ \left.+2\left(\tan ^{-1} \eta_{r}+\tan ^{-1} \eta_{0}\right)\right] & \text { for unstable }\end{cases}
$$


(a)
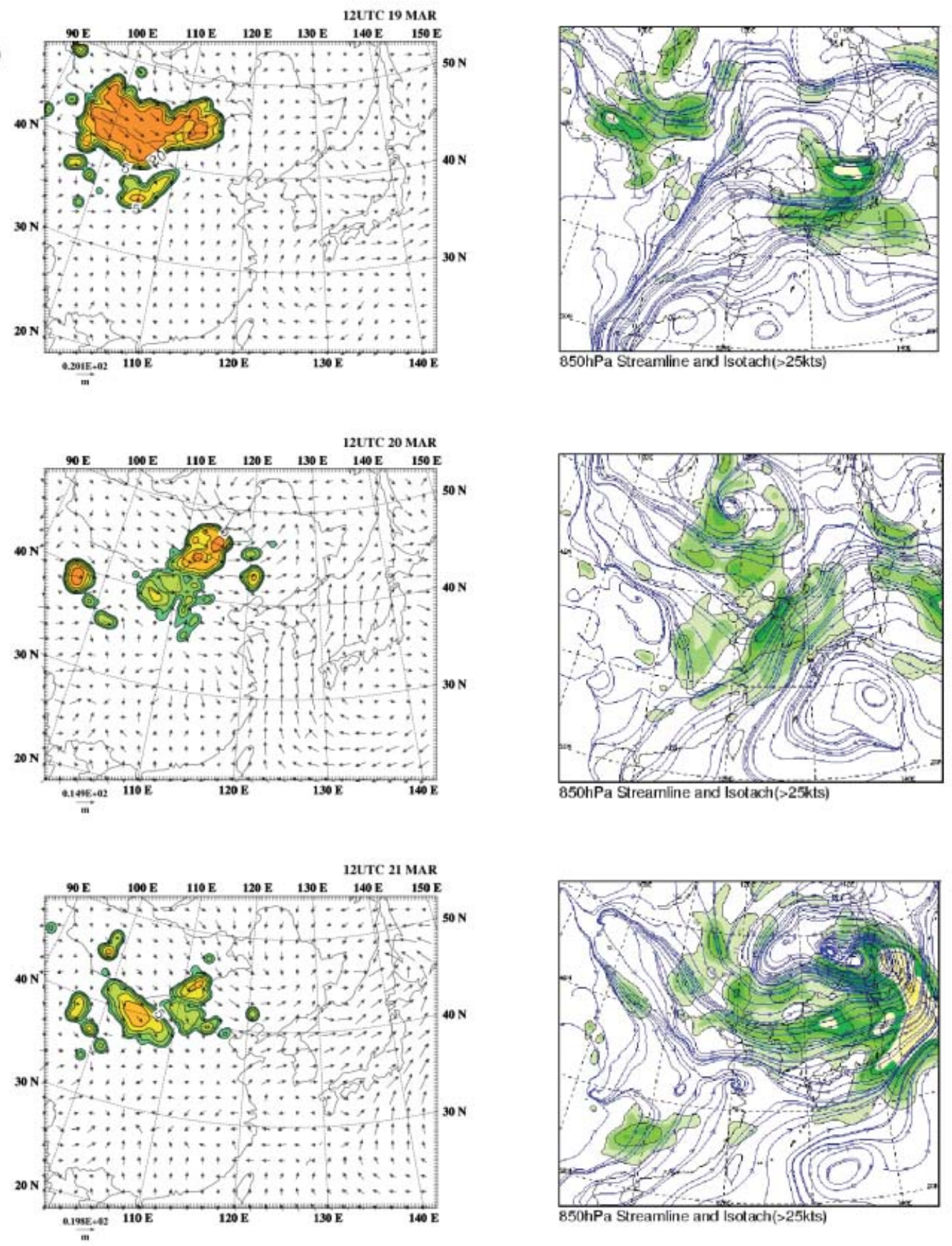

Fig. 2. The dust emission rate $\left(\mathrm{g} \mathrm{m}^{-2} \mathrm{~h}^{-1}\right)$ and $850 \mathrm{hPa}$ streamline with isotach on a) 19,20 , and 21 March and b) 7, 8, and 9 April 2002.

where $u_{*}$ is the friction velocity, $z_{0}$ the surface roughness length, $k$ the von Karman constant, and $\zeta$ the dimensionless height scale given by $z / L, \eta_{0}=\left(1-15 \zeta_{0}\right)^{1 / 4}, \eta_{r}=\left(1-15 \zeta_{r}\right)^{1 / 4}, \zeta_{0}=$ $z_{0} / L, \zeta_{r}=z_{r} / L$, and $z_{r}$ is the reference height.
The quasi-laminar layer resistance $\left(R_{b}\right)$ for the Particle is given by:

$$
R_{b}=\frac{1}{u_{*}\left(S_{c}^{-2 / 3}+10^{-3 / S_{t}}\right)}
$$


(b)
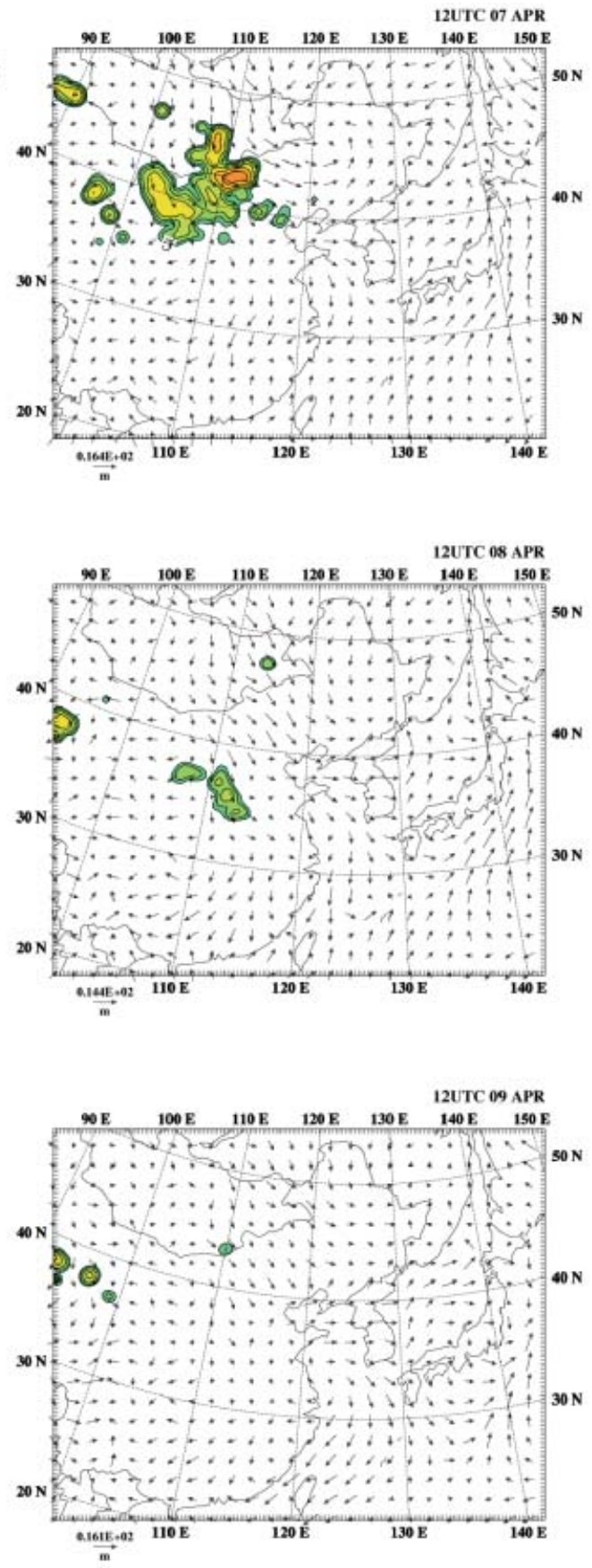

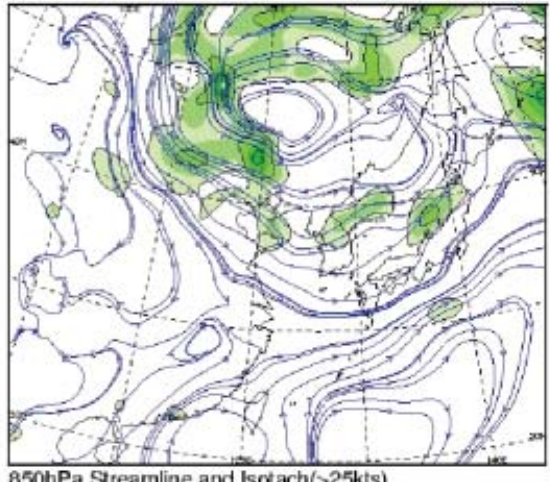

$850 \mathrm{hPa}$ Streamline and $\mathrm{ksotach}(>25 \mathrm{kts})$
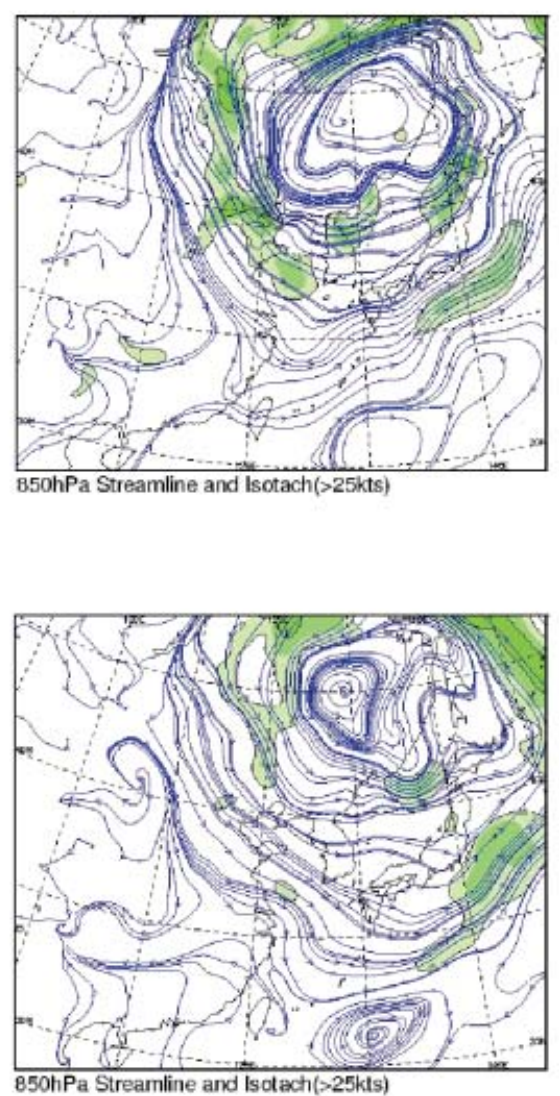

Fig. 2 (continued)

where $S_{c}=\frac{v}{D}$ is the Schmidt number, and $S_{t}=\frac{V_{g} u_{*}^{2}}{g v}$ the Stokes number, $v$ is the kinematic viscosity of air and $D$ the molecular diffusivity of the air.
The gravitational settling velocity $\left(V_{g}\right)$ is from Stokes' law as:

$$
V_{g}=\frac{\rho_{p} g D_{p}^{2}}{18 \mu}
$$



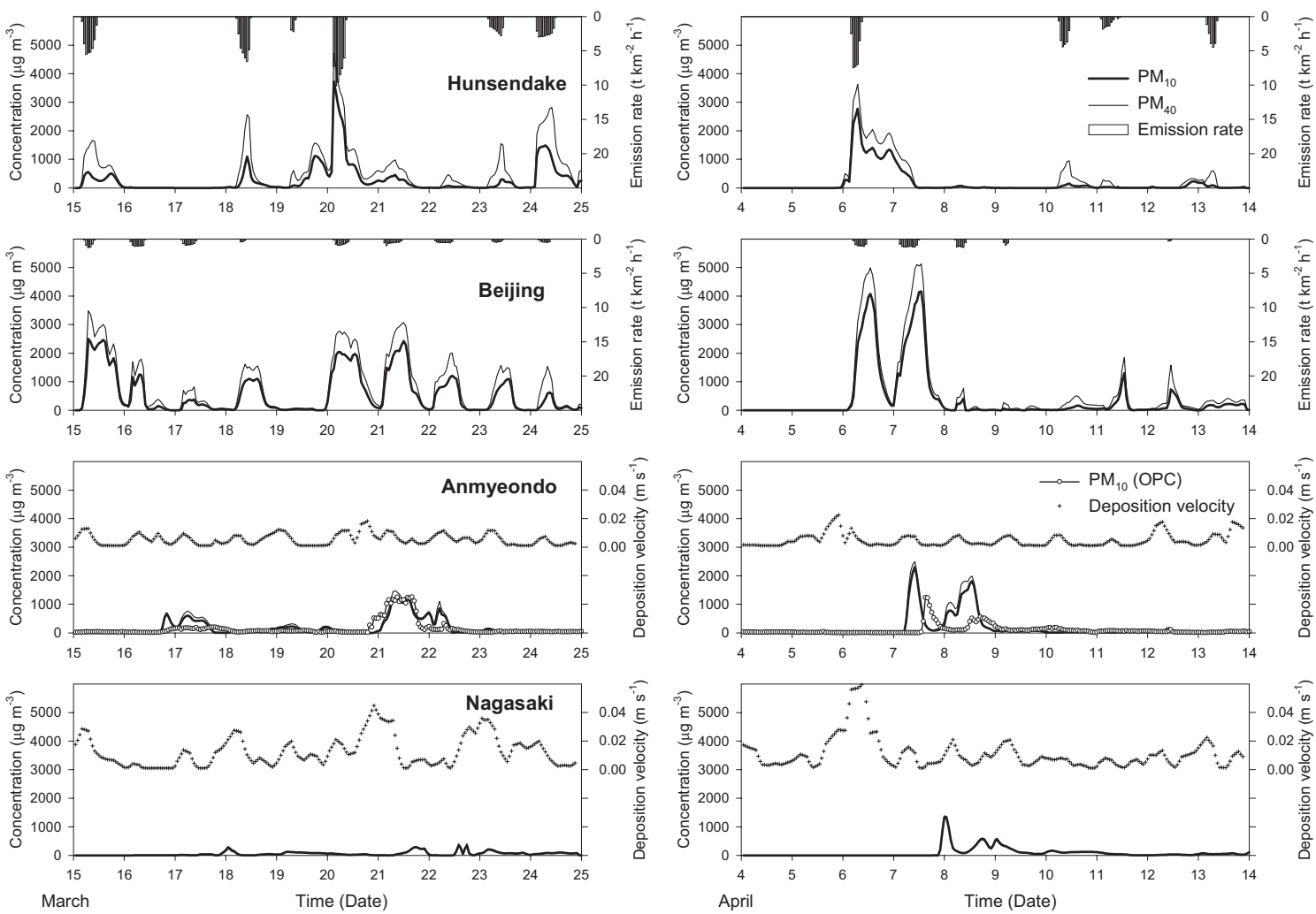

Fig. 3. Temporal variations of $\mathrm{PM}_{10}$ and $\mathrm{PM}_{40}\left(\mu \mathrm{g} \mathrm{m}{ }^{-3}\right)$ with emission rate (vertical bar at Hunsendake and Beijing, $\mathrm{t} \mathrm{km}^{-2} \mathrm{~h}^{-1}$ ) and deposition velocity (+, Anmyeondo and Nagasaki, $\mathrm{m} \mathrm{s}^{-1}$ ) and surface $\mathrm{PM}_{10}$ concentration $\left(\mathrm{O}\right.$, Anmyeondo, $\mu \mathrm{g} \mathrm{m}^{-3}$ ) obtained from OPC.

where $\rho_{p}$ is the density of the particle assumed to be $2600 \mathrm{~kg} \mathrm{~m}^{-3}$ (Park and In 2003; In and Park 2003), $D_{p}$ the particle diameter, $g$ the gravitational acceleration and $\mu$ the dynamic viscosity of air.

\section{Results and discussion}

\subsection{Overview of synoptic features}

Surface synoptic weather maps with dust reports for the Periods I and II are presented in Fig. 1. The left panel in Fig. 1 shows a cyclone system located at northeastern China on 19 March has progressively moved southeastward to locate the East Sea on 21 March with wide regions of dust rise reports behind the cyclone system (Fig. 1a). The pressure gradient associated with the cyclone in Period I is stronger and longer lasted than that in Period II (Fig. 1b). Therefore, the dust reports are continued for 3 days in Period I while those in Period II have remarkably decreased with time.

\subsection{Estimation of dust emission and concentration}

The estimated emission rate $\left(\mathrm{g} \mathrm{m}^{-2} \mathrm{hr}^{-1}\right)$ from $\mathrm{ADAM}$ and $850 \mathrm{hPa}$ streamline with isotach produced by KMA for Periods I and II are shown in Fig. 2. The most intensive dust emission in Period I (Fig. 2a) is found on 19 March 2002 in the border of the central northern part of China and Mongolia and the eastern part of China on 20 and 21 March 2002. However, the dust emission in Period II (Fig. 2b) in the source regions is much weaker than that in Period I with much reduced emission regions. The $850 \mathrm{hPa}$ streamline and isotach ( $>25$ knots) show very strong wind on the $850 \mathrm{hPa}$ level over the emission area. The dust emitted in this region has eventually affected Korea and Japan in both periods. Also note that there is very strong wind on $850 \mathrm{hPa}$ over source regions that is well corresponding to the heavy dust rise region. 
(a)
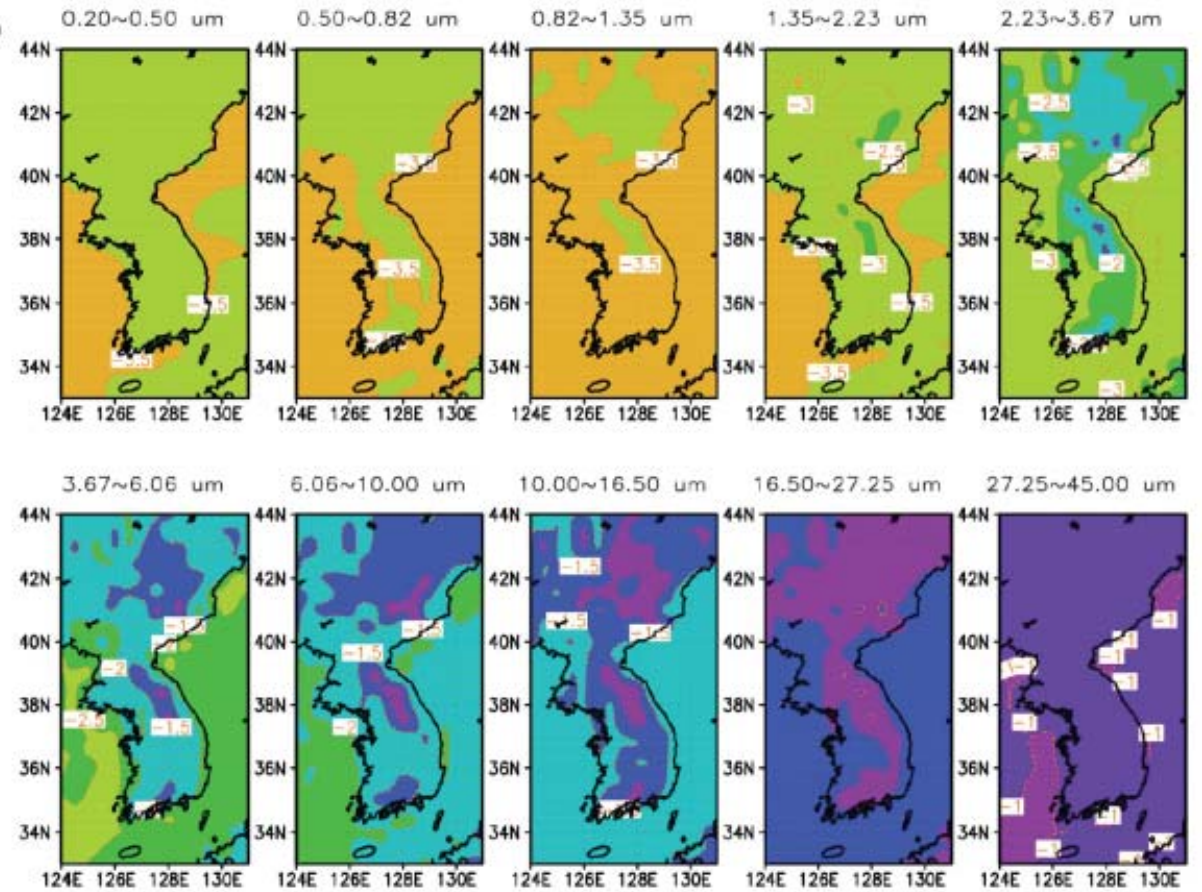

$6.06 \sim 10.00 \mathrm{um}$

$10.00 \sim 16.50$ um

$16.50 \sim 27.25$ um

$27.25 \sim 45.00$ um

124E 126E 128E $130 \mathrm{E}$
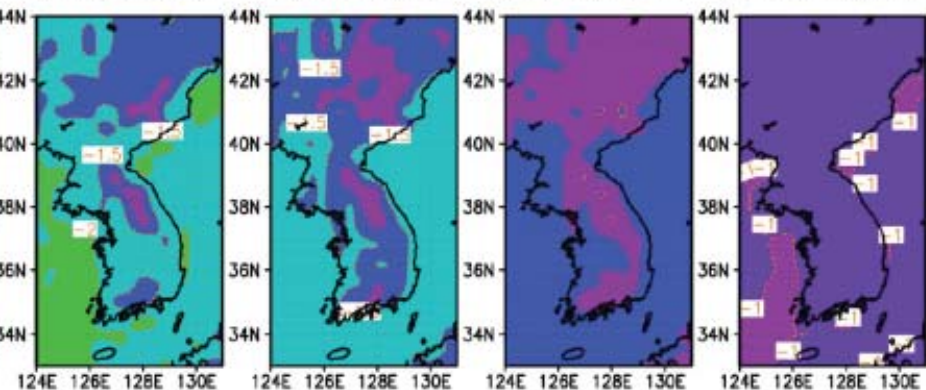

(b)
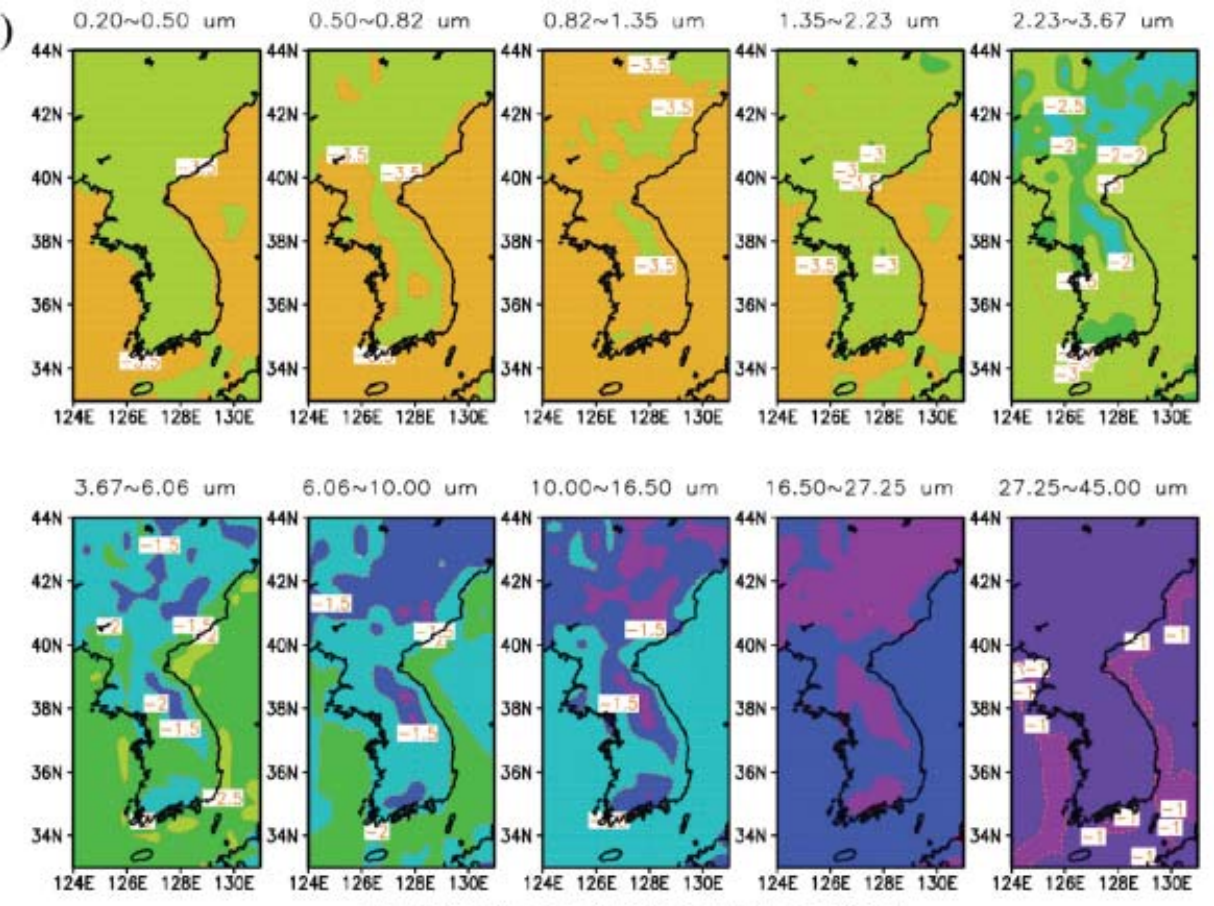

$6.06 \sim 10.00 \mathrm{um}$

$10.00 \sim 16.50$ um

$16.50 \sim 27.25$ um

27.25 45.00 um
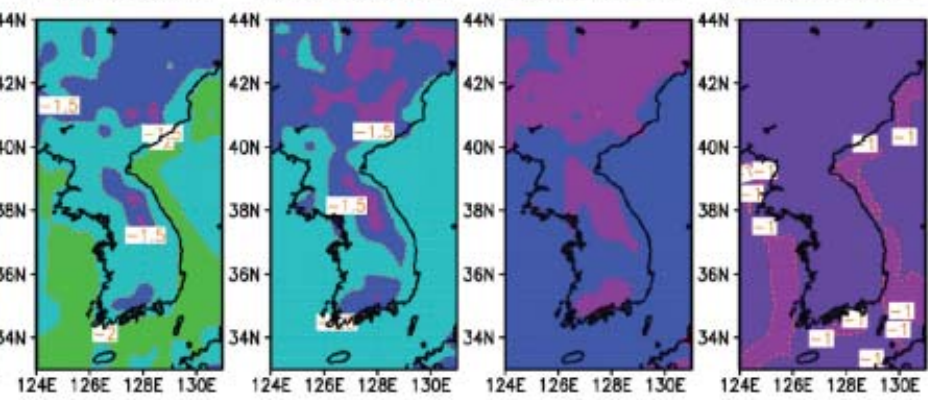

Deposition Velocity $\left(\mathrm{ms}^{-1}\right.$; Common logarithm)

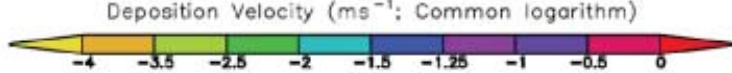

Fig. 4. Spectral and spatial distributions of deposition velocity $\left[\mathrm{m} \mathrm{s}^{-1}\right]$ over the Korean Peninsula for

(a) Period I, and (b) Period II. Contour line represents the power of 10 of the deposition velocity. 
Figure 3 shows the temporal variation of surface concentrations of $\mathrm{PM}_{10}$ and $\mathrm{PM}_{40}$ with the emission rate at Hunsendake and Beijing for both periods. The emission rate $\left(\mathrm{t} \mathrm{km} \mathrm{km}^{-2} \mathrm{~h}^{-1}\right)$ is shown at Hunsendake and Beijing by the vertical bar. The deposition velocity $\left(\mathrm{m} \mathrm{s}^{-1},+\right)$ at Anmyeondo and Nagasaki and also the estimated dust concentration $\left(\mu \mathrm{g} \mathrm{m}{ }^{-3}, O\right)$ by OPC data at Anmyeondo are given in Fig. 3. The surface concentration of modeled $\mathrm{PM}_{10}$ is compared with the observed $\mathrm{PM}_{10}$ concentration from OPC at Anmyeondo. Large emission rates in the dust source region of Hunsendake are found in Period I. The modeled dust concentration at Anmyeondo in Period I starts to increase slightly later than observed concentration but the peak and ending times well coincide with concentration. On the other hand, the modeled starting and ending times of dust event in Period II in Korea are earlier and the peak value is lower than observed concentration by OPC. The deposition velocity averaged for the dust particles less than $10 \mu \mathrm{m}$ in diameter at Anmyeondo shows smaller fluctuation than that at Nagasaki. However, the variations of the dry deposition velocity may not contribute significantly to the total depositions of dust.

\subsection{Estimation of dry deposition}

The variations of deposition velocity with the dust particle size are investigated using the model output over the Korean peninsula for Periods I and II and the results are given in Fig. 4. Since aerodynamic resistance $\left(R_{a}\right)$ is one of the dominant parameters of the deposition velocity and a function of surface roughness length, the regional difference of deposition velocity in the same particle size is dominated by the topography. The results suggest that dramatic differences in deposition velocity are association with the dust particle size. However, Periods I and II do not reflect a noticeable difference, suggesting a similar microphysical atmospheric condition and a constant value of gravitational settling velocity with time (Table 1). Also note that the bin 3 $(0.82-1.35 \mu \mathrm{m}$ in diameter), has the smallest deposition velocity as the Brownian diffusion process halts the movement of particles with diameters larger than $0.05 \mu \mathrm{m}$, whereas particles of 2 to $20 \mu \mathrm{m}$ in diameter are efficiently
Table 1. Gravitational settling velocity, $V_{g}\left[\mathrm{~cm} \mathrm{~s}^{-1}\right]$, and deposition velocity, $V_{d}\left[\mathrm{~cm} \mathrm{~s}^{-1}\right]$, over the Korean peninsula calculated from ADAM.

\begin{tabular}{l|ccc}
\hline \multirow{2}{*}{$\begin{array}{l}\text { Diameter } \\
(\mu \mathrm{m})\end{array}$} & & \multicolumn{2}{c}{$V_{d}\left(\mathrm{~cm} \mathrm{~s}^{-1}\right)$} \\
\cline { 3 - 4 } $0.2-0.5$ & $V_{g}\left(\mathrm{~cm} \mathrm{~s}^{-1}\right)$ & Period I & Period II \\
$0.5-0.82$ & $1.17 \mathrm{E}-03$ & $4.62 \mathrm{E}-02$ & $4.52 \mathrm{E}-02$ \\
$0.82-1.35$ & $8.16 \mathrm{E}-03$ & $3.14 \mathrm{E}-02$ & $3.08 \mathrm{E}-02$ \\
$1.35-2.23$ & $2.33 \mathrm{E}-03$ & $2.72 \mathrm{E}-02$ & $2.69 \mathrm{E}-02$ \\
$2.23-3.67$ & $6.31 \mathrm{E}-02$ & $6.62 \mathrm{E}-02$ & $7.26 \mathrm{E}-02$ \\
$3.67-6.06$ & $1.72 \mathrm{E}-01$ & $1.78 \mathrm{E}+00$ & $1.45 \mathrm{E}+00$ \\
$6.06-10.0$ & $4.67 \mathrm{E}-01$ & $2.71 \mathrm{E}+00$ & $2.44 \mathrm{E}+00$ \\
$10.0-16.5$ & $1.26 \mathrm{E}+00$ & $3.72 \mathrm{E}+00$ & $3.49 \mathrm{E}+00$ \\
$16.5-27.25$ & $3.46 \mathrm{E}+00$ & $5.92 \mathrm{E}+00$ & $5.71 \mathrm{E}+00$ \\
$27.25-45$ & $9.44 \mathrm{E}+00$ & $1.17 \mathrm{E}+01$ & $1.15 \mathrm{E}+01$ \\
$45-74$ & $2.74 \mathrm{E}+01$ & $2.93 \mathrm{E}+01$ & $2.91 \mathrm{E}+01$ \\
\hline
\end{tabular}

transported across the laminar sublayer by inertial impaction. On the other hand, the particles larger than $20 \mu \mathrm{m}$ in diameter are governed by gravitational settling (Seinfeld and Pandis 1998). The gravitational settling velocity for each particle size is shown in Table 1. Since there are large differences between the largest and the smallest particle, the larger particle can be more easily settled on the ground than the smaller particle. The dry deposition amounts estimated by using the deposition velocity and concentration fields over the Korean peninsula are presented in Fig. 5. Figure 5 shows that the deposition amount is quite similar for the bins from 1 to $5(0.20-$ $3.67 \mu \mathrm{m})$ but remarkable variations are noticed for the bins higher than $6\left(D_{p}>3.67 \mu \mathrm{m}\right)$, suggesting the effectiveness of the gravitational settling velocity of larger particles on the dry deposition.

The dry deposition of Asian dust over North Korea, South Korea, and Japan for each period is estimated in grids of 161, 141 and 533, respectively (Fig. 6). Dry depositions derived from ADAM are compared with observations obtained from the spectral number concentrations using OPC. For retrieving the dry deposition using OPC data, the spectral number concentration is converted to the spectral mass concentration by assuming a spherical shape of a particle with a constant density of $2,600 \mathrm{~kg} \mathrm{~m}^{-3}$ (Park and In 2003; In and Park 2003; Park and 
(a)
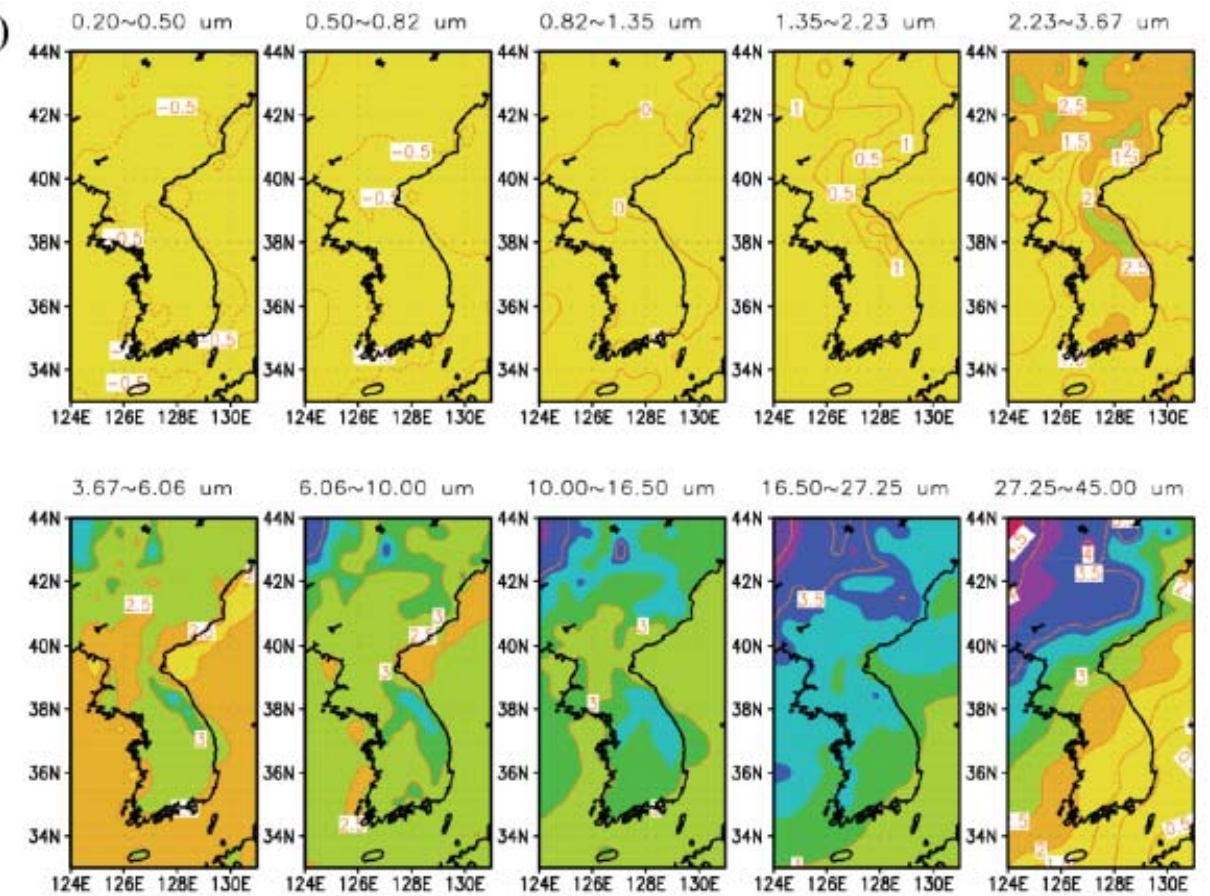

$6.06 \sim 10.00$ um

$10.00 \sim 16.50 \mathrm{um}$

$16.50 \sim 27.25 \mathrm{um} \quad 27.25 \sim 45.00 \mathrm{um}$
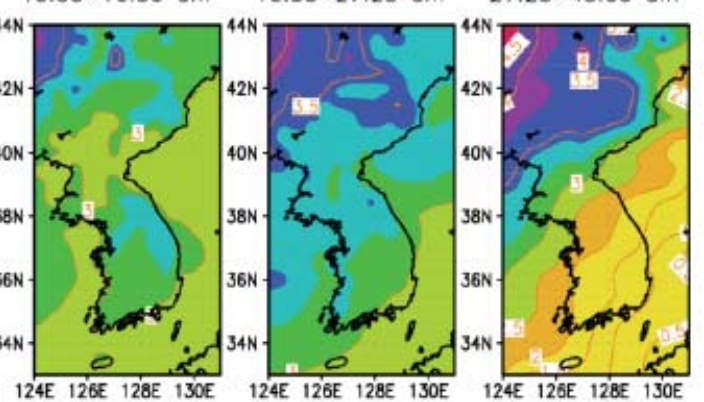

(b)
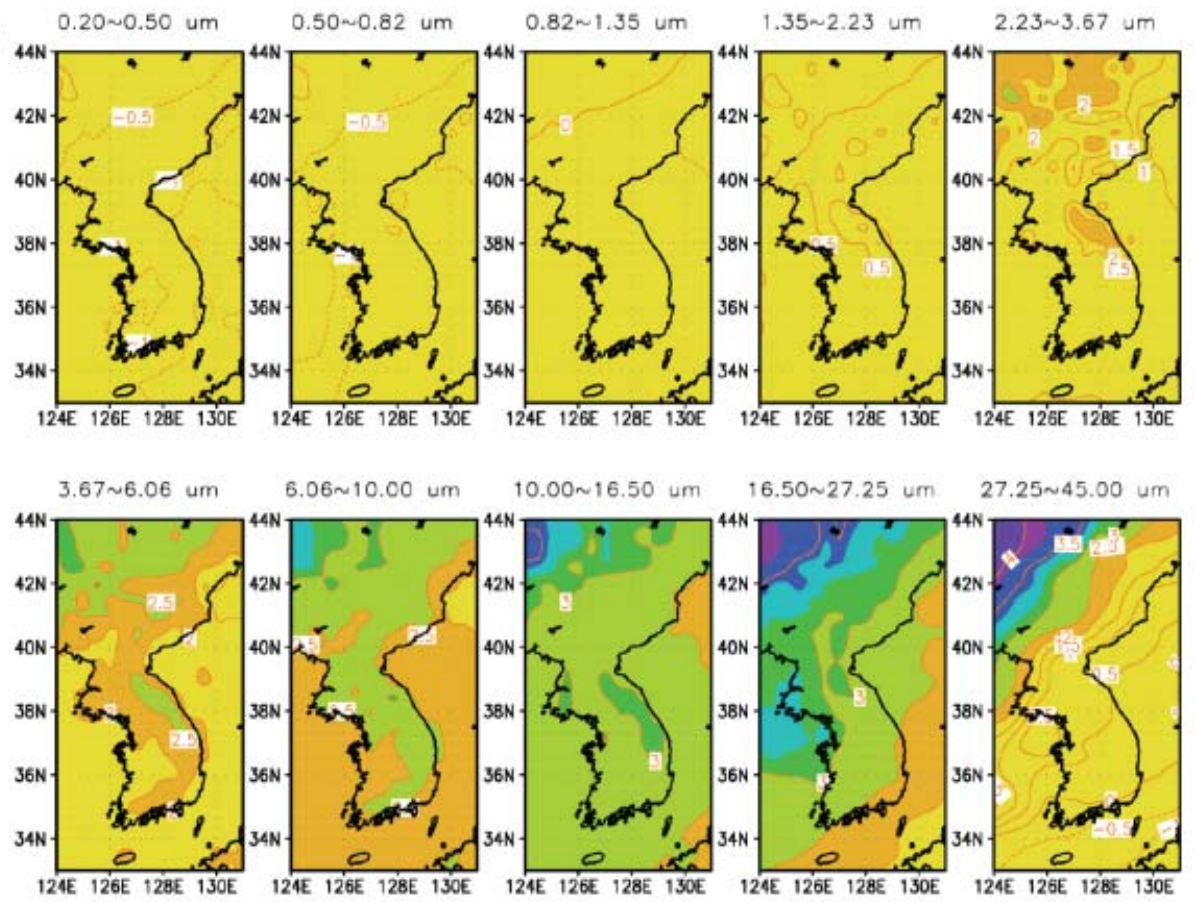

$6.06 \sim 10.00 \mathrm{um}$

$10.00 \sim 16.50$ um

$16.50 \sim 27.25 \mathrm{um}$

$27.25 \sim 45.00 \mathrm{um}$
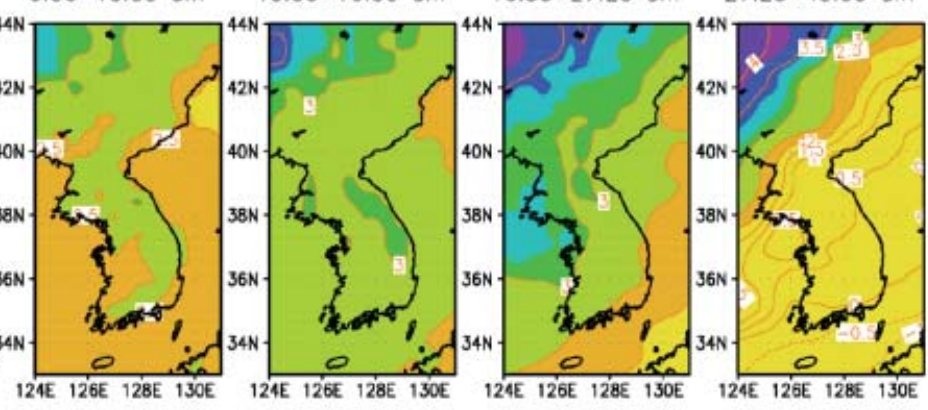

Dry Deposition ( $\mathrm{kg} \mathrm{km}^{-2}$; Common logarithm)

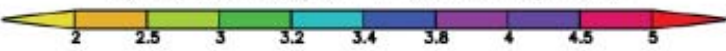

Fig. 5. The same as in Fig. 4 except for total dry deposition $\left[\mathrm{kg} \mathrm{km}^{-2}\right]$ for (a) Period I and (b)

Period II. 


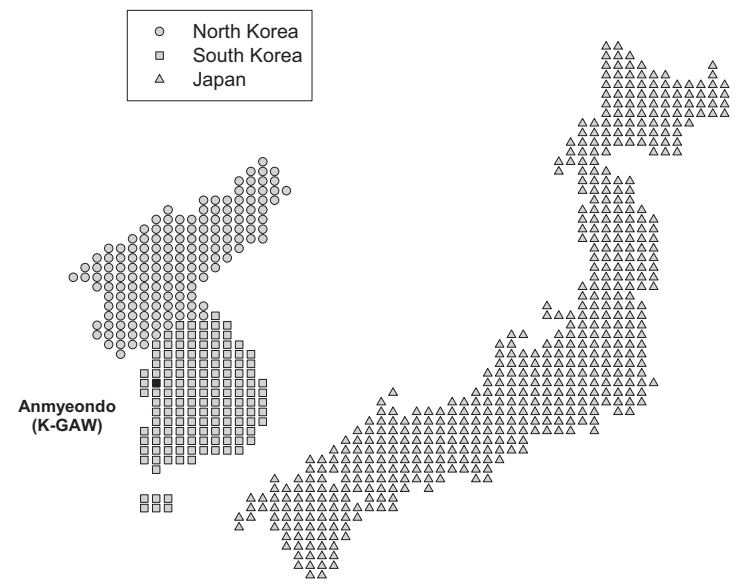

Fig. 6. The grid scheme used in the calculation of dry deposition over North Korea $(\bigcirc, n=161)$, South Korea $(\square$, $n=141)$, and Japan $(\triangle, n=533)$. Each grid has the area of $30 \mathrm{~km} \times 30 \mathrm{~km}$. Korea GAW station of Anmyeondo is marked with a dark square in South Korea.

Lee 2004). Then, dry deposition is retrieved by Eq. (1) with the dry deposition velocity simulated by ADAM. The modeled dry deposition for each bin is compared with that at Anmyeondo in Korea using OPC data and the results are shown in Table 2. The correlation coefficients between the ADAM and OPC results for Periods I and II are 0.78 and 0.54 , respectively. The highest and the lowest correlations at each bin for Periods I and II are 0.88, 0.27 and 0.73, 0.15 , respectively. Note that dry deposition at bin 8 has four order of magnitude higher than that at bin 1 , suggesting more effectiveness of larger particles on dry deposition.

The comparison of time series of dry deposition derived from ADAM and OPC in the same diameter range of 1.35 to $2.23 \mu \mathrm{m}$ for each Period is presented in Fig. 7. The estimated dry deposition using the model overestimates during weak Asian dust events such as on 17, 19, 20 March (Fig. 7a). In the intense Asian dust events, on the other hand, ADAM slightly underestimates the dry deposition compared with the observation. On the whole, however, dry deposition derived from ADAM and OPC has a reasonable correlation of 0.83 in Period I. Slight overestimation and underestimation are found on 8, 13 and 10,11 April, respectively (Fig. 7b). However, correlation coefficient is found to be 0.73 . The discrepancy of dry deposition between ADAM and OPC may be contributed by the assumptions of the spherical shape and a constant density of the particle and the different horizontal resolution between the model and the observation site.

Table 2. Comparison of total spectral dry deposition flux estimated by model (ADAM) with observation (OPC) for Periods I and II.

\begin{tabular}{l|cc|c|cc|c}
\hline \multirow{2}{*}{ Diameter $(\mu \mathrm{m})$} & \multicolumn{5}{c}{ Integrated dry deposition $\left(\mathrm{kg} \mathrm{km}^{-2}\right)$} \\
\cline { 2 - 7 } & \multicolumn{2}{|c}{ Period I: $15-24$ March 2002} & \multicolumn{2}{c}{ Period II: 4-13 April 2002 } \\
\cline { 2 - 7 } $0.2-0.5(\mathrm{ADAM})$ & $\mathrm{ADAM}$ & OPC & $R^{2}$ & ADAM & OPC & $R^{2}$ \\
$0.3-0.5(\mathrm{OPC})$ & $3.98 \mathrm{E}-01$ & $6.45 \mathrm{E}-01$ & 0.60 & $1.05 \mathrm{E}-01$ & $7.13 \mathrm{E}-01$ & $0.15^{* *}$ \\
$0.5-0.82$ & $5.11 \mathrm{E}-01$ & $5.05 \mathrm{E}-01$ & 0.88 & $1.87 \mathrm{E}-01$ & $3.44 \mathrm{E}-01$ & 0.42 \\
$0.82-1.35$ & $1.34 \mathrm{E}+00$ & $1.27 \mathrm{E}+00$ & $0.88^{*}$ & $6.17 \mathrm{E}-01$ & $7.16 \mathrm{E}-01$ & 0.64 \\
$1.35-2.23$ & $5.94 \mathrm{E}+00$ & $4.24 \mathrm{E}+00$ & 0.83 & $3.00 \mathrm{E}+00$ & $2.43 \mathrm{E}+00$ & $0.73^{*}$ \\
$2.23-3.67$ & $4.50 \mathrm{E}+01$ & $7.66 \mathrm{E}+01$ & $0.27^{* *}$ & $1.46 \mathrm{E}+01$ & $2.92 \mathrm{E}+01$ & 0.37 \\
$3.67-6.06$ & $4.24 \mathrm{E}+02$ & $5.59 \mathrm{E}+02$ & 0.79 & $9.03 \mathrm{E}+01$ & $1.14 \mathrm{E}+02$ & 0.60 \\
$6.06-10.0$ & $9.58 \mathrm{E}+02$ & $8.47 \mathrm{E}+02$ & 0.84 & $3.29 \mathrm{E}+02$ & $2.75 \mathrm{E}+02$ & 0.53 \\
$10.0-16.5(\mathrm{ADAM})$ & $1.65 \mathrm{E}+03$ & $1.29 \mathrm{E}+03$ & 0.72 & $9.66 \mathrm{E}+02$ & $6.28 \mathrm{E}+02$ & 0.45 \\
$10.0-25.0(\mathrm{OPC})$ & & & & & & \\
\hline TOTAL & $3.08 \mathrm{E}+03$ & $2.78 \mathrm{E}+03$ & 0.78 & $1.40 \mathrm{E}+03$ & $1.05 \mathrm{E}+03$ & 0.54 \\
\hline
\end{tabular}

*: the highest correlation

**: the lowest correlation 
(a)

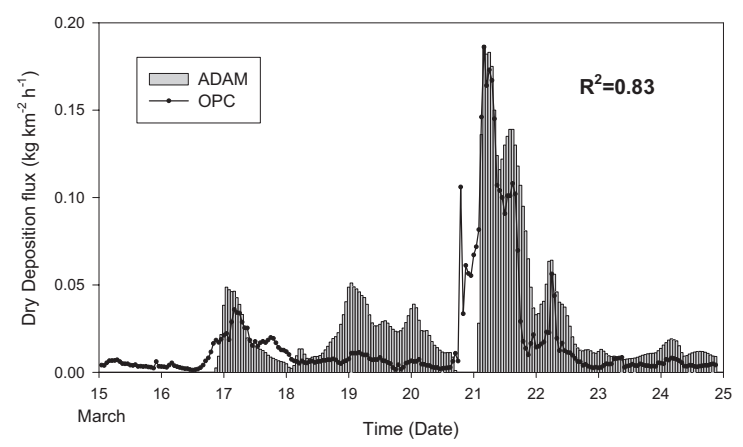

(b)

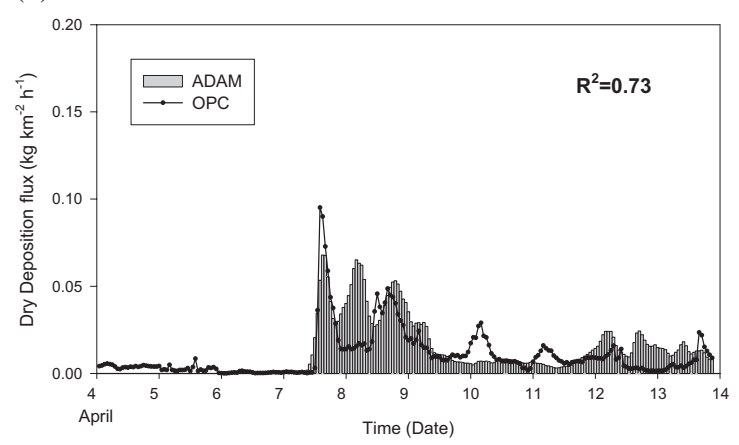

Fig. 7. Time variations of dry deposition flux $\left(\mathrm{kg} \mathrm{km}^{-2} \mathrm{~h}^{-1}\right)$ from model (vertical bar) and observation (closed circle) for the particle size of 1.35 to $2.23 \mu \mathrm{m}$ in diameter at Anmyeondo for the (a) Period I, and (b) Period II.

The estimated dry deposition amount over each country for Periods I and II are shown in Table 3 and Fig. 8. Figure 8 clearly indicates the importance of the distance from the source regions. More than $40 \%$ of total deposition of three countries (Table 3 ) occurs over North Korea due to its nearness to the Asian dust source region. The total deposition amount in Japan for Period II is higher than that in South Ko- rea. However the deposition flux in Japan is lower than that in South Korea. The averaged total dry deposition flux for Periods I and II is found to be $9.10,6.29$, and 1.93 ton $\mathrm{km}^{-2}$ over North Korea, South Korea, and Japan, respectively, suggesting a significant reduction of dust deposition away from the source region.

\section{Summaries and conclusions}

We have examined size dependent Asian dust dry deposition using ADAM for the spring of 2002. Estimation of dry deposition of Asian dust has been carried out using the ADAM model with the meteorological data (RDAPS) from the Korea Meteorological Administration and the results are compared with those obtained by the observed OPC data. Results indicate that both estimations have a good correlation with the correlation coefficient of 0.78 in Period I (15-24 March, 2002) and 0.54 in Period II (4-13 April 2002).

The amounts of dry deposition over the Korean peninsula and Japan in Period I are higher than in Period II. The estimated total dry deposition amounts over the South Korea, North Korea and Japan are found to be about 558, 955, and $729 \mathrm{k}$ ton, respectively in Period I and about 240, 364, and $196 \mathrm{k}$ ton, respectively in Period II. The averaged total dry deposition flux is $52.5,36.3$, and $11.1 \%$ over North Korea, South Korea, and Japan, respectively, suggesting that the intensity of dry deposition decreases as it gets farther from the source region.

The estimated spectral deposition velocity is found to vary with the particle size having a minimum at bin 3 due to the nature of Brownian diffusion, inertial impaction, and gravitational settling. However, the deposition velocity in Periods I and II is not significant, suggesting a similar microphysical atmospheric conditions in both periods. The spectral dry deposition in-

Table 3. Dry deposition over North Korea, South Korea, and Japan for Periods I and II.

\begin{tabular}{l|c|c|c|c|c|c|c|c}
\hline \multirow{4}{*}{ Region } & \multicolumn{2}{|c|}{$\begin{array}{c}\text { North Korea } \\
(n=161)\end{array}$} & \multicolumn{2}{c|}{$\begin{array}{c}\text { South Korea } \\
(n=141)\end{array}$} & \multicolumn{2}{c|}{$\begin{array}{c}\text { Japan } \\
(n=533)\end{array}$} & \multicolumn{2}{c}{$\sum(\mathrm{NK}+\mathrm{SK}+\mathrm{JP})$} \\
\cline { 2 - 9 } Case & $\begin{array}{c}\text { Total } \\
{[\text { ton] }}\end{array}$ & $\begin{array}{c}\text { Ave. } \\
{\left[\text { ton km }{ }^{-2}\right]}\end{array}$ & $\begin{array}{c}\text { Total } \\
{[\text { ton] }}\end{array}$ & $\begin{array}{c}\text { Ave. } \\
{\left[\text { ton km }{ }^{-2}\right]}\end{array}$ & $\begin{array}{c}\text { Total } \\
{[\text { ton] }}\end{array}$ & $\begin{array}{c}\text { Ave. } \\
{\left[\text { ton km }{ }^{-2}\right]}\end{array}$ & $\begin{array}{c}\text { Total } \\
{[\text { ton] }}\end{array}$ & $\begin{array}{c}\text { Ave. } \\
{\left[\text { ton km } \mathrm{km}^{-2}\right]}\end{array}$ \\
\hline Period I & 954,521 & 6.59 & 557,736 & 4.40 & 728,739 & 1.52 & $2,241,080$ & 2.98 \\
Period II & 363,836 & 2.51 & 240,278 & 1.89 & 196,230 & 0.41 & 800,344 & 1.06 \\
\hline
\end{tabular}


(a)

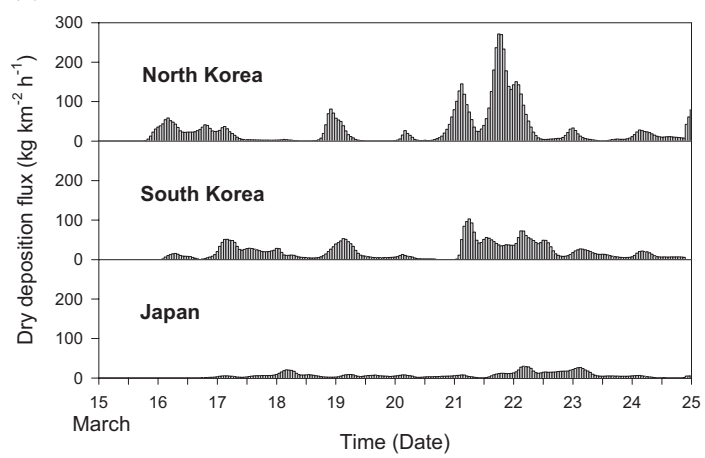

(b)

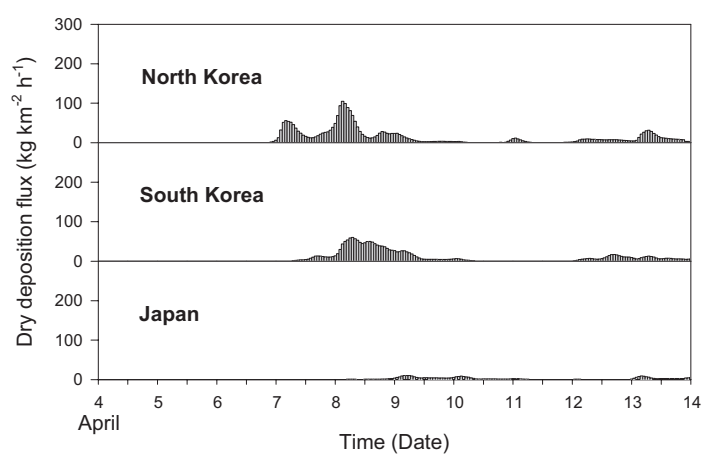

Fig. 8. Time variations of dry deposition flux $\left(\mathrm{kg} \mathrm{km}^{-2} \mathrm{~h}^{-1}\right)$ over North Korea, South Korea, and Japan for the (a) Period I, and (b) Period II.

dicates that the particles larger than $3.67 \mu \mathrm{m}$ in diameter are dominant to the dry deposition, due to the higher settling velocity.

This study is mainly pertained to dry deposition amount in the downstream region from the source using the ADAM model. To estimate more accurate dry deposition amount requires more precise dust emission amount in the source region. Also, this study indicates that the parameterization of dry deposition of Asian dust may be a prerequisite to assess the impact of Asian dust. In the next step, we will investigate more detailed features of deposition velocity and parameterization of emission of Asian dust from the source region.

\section{Acknowledgements}

This study was performed for the project, "Development on the Asian dust (Hwangsa) Monitoring and Prediction Techniques (II)", one of the Meteorology and Earthquake R\&D pro- grams funded by the Korea Meteorological Administration.

\section{References}

Bai, N., K. Zhang, 2001. About Sandstorms in China, 2000-2001. Proceedings of Seventh International Joint Seminar on the Regional Deposition Process in the Atmosphere, 129-135.

Chun, Y., J. Kim, J.C. Choi, K.O. Boo, S.N. Oh, M. Lee, 2001a. Characteristic number size distribution of aerosol during Asian dust period in Korea. Atmospheric Environment 35, 27152721.

, K.O. Boo, J. Kim, S.-U. Park, M. Lee, 2001 b. Synopsis, transport, and physical characteristics of Asian dust in Korea. Journal of Geophysical Research 106, 18461-18469.

- S.W. Kim, K.M. Cho, J.S. Kim, 2003. One hundred year records of Asian Dust in Korea, Global Environmental Research, Association of International Research Institute for Environmental Studies, 7(2), 225-231. (In Japanese)

- J.Y. Lim, 2004. The recent characteristics of Asian Dust and Haze events in Seoul, Korea. Meteorology and Atmospheric Physics 87, 143152.

Chung, Y.S., M.B. Yoon, 1996. On the Occurrence of Yellow Sand and Atmospheric Loadings, Atmospheric Environment 30, 2387-2397.

Duhdia, J., D. Grill, Y.R. Guo, K. Manning, J. Michalakes, W. Wang, and J. Wilson, PSU/NCAR Mesoscale modeling system tutorial class note and User's Guide: MM5 modeling system version 3, Nat'l Cent. for Atmos. Res., Boulder, Colo., 2001.

Grell, G.A., J. Duhdia, and D.R. Stauffer, A description of the $5^{\text {th }}$ generation Penn State/NCAR mesoscale model (MM5), NCAR Tech. Note NCAR/TN-398, 117 pp., Nat'l. Cent. for Atmos. Res., Boulder, Colo., 1994.

In, H.-J., S.-U. Park, 2002. A simulation of longrange transport of Yellow Sand observed in April 1998 in Korea. Atmospheric Environment 36, 4173-4187.

- , 2003. The soil particle size dependent emission parameterization for and Asian dust (Yellow Sand) observed in Korea on April 2002. Atmospheric Environment 37, 4625-4636.

Lu, H., Y. Shao, 1999. A new model for dust emission by saltation bombardment. Journal of Geophysical Research 104, 16827-16842.

Park, S.-U., 2002. Field survey of Yellow Sand source regions. Proceedings of workshop of Asian dust, 22 March, 2002, Korea Meteorological Administration, Korea. 
and H.-J. In, 2003. Parameterization of dust emission for the simulation of the Yellow Sand (Asian dust) observed in March 2002 in Korea. Journal of Geophysical Research 108 (D19), 4618 (doi:10.1029/2003JD003484).

and E.-H. Lee, 2004. Parameterization of Asian dust (Hwangsa) particle-size distributions for use in dust emission models. Atmospheric Environment 38, 2155-2162.

Seinfeld, J.H. and S.N. Pandis, 1998. Atmospheric Chemistry and Physics. Wiley-Interscience, New-York, 1326 pp.

Shao, Y., 2001. A model of mineral dust emission. Journal of Geophysical Research 106, 2023920254.

, E. Jung and L.M. Leslie, 2002. Numerical prediction of northeast Asian dust storms using an integrated wind erosion modeling system. Journal of Geophysical Research $\mathbf{1 0 7}$ (D24), 4814 (doi:10.1029/2001JD001493).

Wesely, M.L. and B.B. Hicks, 1977. Some factors that affect the deposition rated of sulfur dioxide and similar gases on vegetation. Journal of Air pollution Control Association 27, 1110-1117.

- and -2000 . A review of the current status of knowledge on dry deposition. Atmospheric Environment 34, 2261-2282.

- D.R. Cook, R.L. Hart, and R.E. Speer, 1985. Measurements and parameterization of particulate sulfur dry deposition over grass. Journal of Geophysical Research 90, 2131-2143.

Westphal, D.L., O.B. Toon, and T.N. Carlson, 1987. A two-dimensional Investigation of the dynamics and microphysics of Saharan dust storms. Journal of Geophysical Research 92, 3027-3049.

- - - , and 1988. A case study of mobilization and transport of Saharan dust, Journal of Atmospheric Science 45, 2145-2175.

Yi, H., 1986. The soil atlas of China, in Academia Sinica, pp. 1-12, Cartogr. Publ., Beijing, China. 